\title{
Upper-limb joint kinetics expression during wheelchair propulsion
}

\author{
Melissa M. B. Morrow, BS; Wendy J. Hurd, PT, PhD; Kenton R. Kaufman, PhD; Kai-Nan An, PhD* \\ Department of Orthopedic Surgery, Mayo Clinic, Rochester, MN
}

\begin{abstract}
In the wheelchair propulsion literature, it is common to report upper-limb (UL) joint kinetics to express shoulder, elbow, and wrist loads. Choosing the appropriate kinetic resolution coordinate system (CS) for UL joint forces and moments has become a laboratory-specific process. The differences that arise during interpretation may hinder a clear and broad understanding of UL joint kinetics during wheelchair propulsion. This article addresses the inconsistency of kinetic reporting in the wheelchair literature that examines the pain and injury experienced by manual wheelchair users. To highlight the variety of reporting methods in wheelchair propulsion, this article surveys peer-reviewed, published articles reporting wrist-, elbow-, or shoulder-joint intersegmental forces and moments calculated from inverse dynamics during wheelchair propulsion. To correct this inconsistency, researchers may need to standardize kinetic reporting methods to achieve a cohesive comprehension of wheelchair biomechanics. This article is provided to open discussion on the anatomical and clinical relevance of currently employed CSs and other available options, with the additional goal of providing an initial recommendation for kinetic representation during wheelchair propulsion.
\end{abstract}

Key words: biomechanics, coordinate system, elbow, forces, joint kinetics, manual wheelchair propulsion, moments, rehabilitation, shoulder, upper limb, wrist.

\section{INTRODUCTION}

The quantification of mechanical loads has given us insight into the connection between wheelchair propulsion and the high incidence of upper-limb (UL) pathology in the manual wheelchair-user population [1-6]. Mercer et al. reported that manual wheelchair users who demonstrated larger shoulder-joint forces and moments during level wheelchair propulsion were more likely to exhibit signs of shoulder pathology on magnetic resonance imaging examination than those demonstrating smaller kinetics [7]. Mercer et al. highlighted the value of joint kinetics as a metric in investigating mechanisms underlying the development of UL pain among manual wheelchair users [7]. Before and subsequent to this article, many investigators have reported UL joint kinetics approximating the mechanical load experienced by the shoulder, elbow, and wrist during wheelchair activities [7-17].

A variety of methods have been adopted for reporting UL joint kinetics. Boninger et al. were the first in wheelchair propulsion literature to express the necessity of reporting joint kinetics in a local segment coordinate system (CS) when the goal is to relate biomechanical data to injury [8]. Boninger et al. explained that the local CS should be anatomically relevant and, hence, linked to physiological-based motions and pathologies [8]. While the trend has been to express joint kinetics in a local CS as opposed to a global reference, varied definitions and combinations of proximal and distal CSs have been used for the UL. One frequently used approach has been to

\footnotetext{
Abbreviations: $\mathrm{CS}=$ coordinate system, ISB $=$ International Society of Biomechanics, JCS = joint CS, UL = upper limb.

*Address all correspondence to Kai-Nan An, PhD; Mayo Clinic, Guggenheim Building 1-28, 200 First Street SW, Rochester, MN 55905; 507-538-1717; fax: 507-284-5392. Email: an.kainan@mayo.edu

DOI:10.1682/JRRD.2008.12.0165
} 
express both the intersegmental joint forces and moments with the proximal CS $[7,11,14,16-17]$. A recent multisite study by Collinger et al. reported shoulder forces in the CS of the segment proximal to the joint and shoulder moments in the CS of the segment distal to the joint [12]. Another option for kinetic representation, though not one regularly employed in the wheelchair literature, is the nonorthogonal joint CS (JCS), which uses a combination of axes from segments both proximal and distal to the joint [18]. The International Society of Biomechanics (ISB) recommends using a nonorthogonal JCS for UL kinematics, but a similar recommendation for UL kinetics does not exist [18]. Without a clear standard for use in UL kinetics, the variety of available options for data representation can confound clinical interpretation.

Choosing the appropriate kinetic resolution CS has become a laboratory-specific process and may hinder a clear and broad understanding of UL joint kinetics during wheelchair propulsion. To correct this inconsistency, researchers need to standardize kinetic reporting methods to achieve cohesive comprehension of wheelchair biomechanics. We provide this article to open discussion on the anatomical and clinical relevance of currently employed CSs and other available options, with the additional goal of providing an initial recommendation for kinetic representation during wheelchair propulsion.

\section{METHODS}

Local segment CSs are commonly placed at either the proximal or distal end of a segment and are generally located at a joint center. After performing an inverse dynamics procedure to calculate intersegmental joint forces and moments, the investigators can represent the kinetics in any CS their marker set allows them to define. Joint forces are most often represented in either an orthogonal proximal or distal segment embedded CS (Table 1 and Figure). Joint moments can be reported in an orthogonal proximal or distal segment-based CS similar to joint forces, but joint moments can also be reported in a nonorthogonal JCS (Table 1 and Figure). The nonorthogonal JCS comprises (1) a fixed axis in the proximal segment, (2) a fixed axis in the distal segment, and (3) a floating axis. To highlight the various reporting methods in wheelchair propulsion, we surveyed peer-reviewed, published articles reporting wrist-, elbow-, or shoulderjoint intersegmental forces and moments calculated from inverse dynamics during wheelchair propulsion. We performed the literature search in PubMed, Medline, and Scopus using combinations of the following search terms: "kinetics," "wheelchair propulsion," "upper limb," "shoulder," "elbow," and "wrist.” From the full collection of articles addressing UL kinetics during wheelchair propulsion, we chose a subset for presentation here. We chose the subset to characterize the full variety of data representation in the field without overlapping methods used by the same investigator.

\section{RESULTS}

Joint kinetics during wheelchair propulsion have been reported for UL joints with various reporting techniques

Table 1.

Resolution coordinate system (CS) definitions for upper-limb joint forces and moments.

\begin{tabular}{|c|c|c|c|}
\hline Joint & Distal Segment & Proximal Segment & Joint CS Definition \\
\hline Shoulder & Upper arm & Trunk & $\begin{array}{l}z-X-Z \text { order } \\
\text { e1: } x \text {-axis fixed in trunk CS } \\
\text { e3: axial rotation around } z \text {-axis of upper arm } \\
\text { e2: axis fixed in upper-arm CS coincident with } x \text {-axis of upper arm }\end{array}$ \\
\hline Elbow & Forearm & Upper arm & $\begin{array}{l}y-x-z \text { order } \\
\text { e1: axis fixed in proximal CS coincident with upper-arm } y \text {-axis } \\
\text { e3: axis fixed in distal CS coincident with } z \text {-axis of forearm } \\
\text { e2: mutually perpendicular varus/valgus rotation axis }\end{array}$ \\
\hline Wrist & Hand & Forearm & $\begin{array}{l}y-x-z \text { order } \\
\text { e1: axis fixed in proximal CS coincident with forearm } y \text {-axis } \\
\text { e3: axis fixed in distal CS coincident with } z \text {-axis of hand } \\
\text { e2: mutually perpendicular ulnar/radial deviation axis }\end{array}$ \\
\hline
\end{tabular}




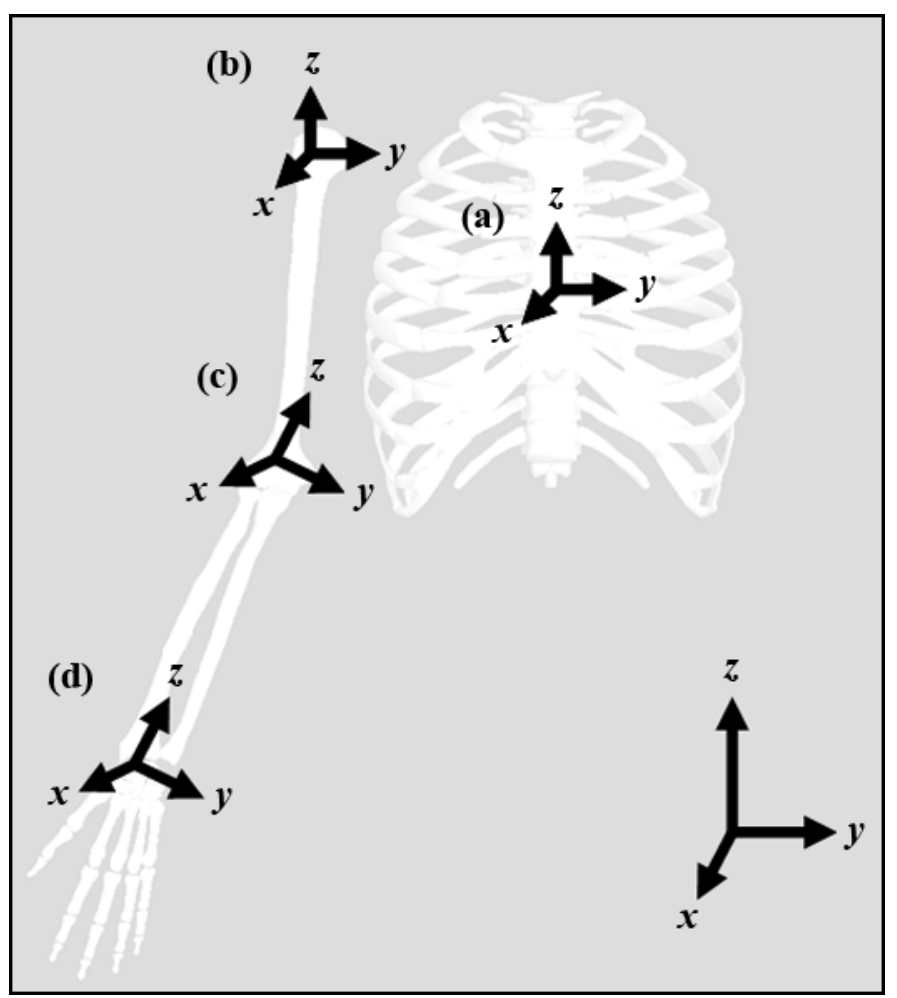

Figure.

Segment coordinate systems for joint forces of (a) trunk, (b) upper arm, (c) forearm, and (d) hand.

(Table 2). The majority of wrist, elbow, and shoulder forces were reported using the proximal CSs (forearm, humerus, and trunk, respectively). We found one exception: Boninger et al. expressed wrist forces in the distal plane using a hand CS with the origin at the wrist center [8]. The elbow-joint forces were generally expressed in the humerus CS centered at the shoulder-joint center [15]. The proximal CS origin for the shoulder joint was placed either at the acromion, shoulder-joint center, or trunk midline [7,12,14-15,19]. An older study performed by Kulig et al. expressed the shoulder forces in a global laboratory CS, but this practice has not been repeated in the literature [10].

A wide spectrum of CSs has been used to report joint moments (Table 2). Sabick et al. reported moments at all joints using a combination of axes from the distal and proximal segments in which the transverse rotation moment of a joint was reported in the distal segment and the frontal and sagittal plane moments were reported in the proximal CS [15]. Many of the articles have represented the moment in the CS proximal to the joint, although the locations of the CS origins varied between articles [7,14,16-17,19-20]. The remaining articles reported the moments in the CS distal to the joint $[8,10,12]$.

\section{DISCUSSION}

The central concern over which CS to choose is in the value of the clinical interpretation. If the clinical interpretation focuses on injury prevention, then joint anatomy and joint pathologies should guide CS selection. Common to all the joint pathologies is their etymological proximity to the joint itself; therefore, any joint kinetics used to describe the load on a particular joint should be reported in a CS centered in the joint itself, whether it is proximal or distal to the joint. While the previous statement may seem like common sense, this article shows that many published joint forces and moments have been expressed in local CSs with their origin away from the focus joint. For example, shoulder-joint forces and moments have been reported in a trunk CS originating in the middle of the trunk and not near the shoulder joint [12,15-16]. An essential component to a clinically relevant reporting system is placing the CS origin near the joint center for both joint forces and moments.

To address injury exploration and prevention in regards to wheelchair propulsion, we must consider the particular pathologies commonly afflicting this population and relate them to kinetic representation. The most commonly reported shoulder pathologies are impingement syndrome and joint instability. Posterior-lateral instability of the proximal ulna occurs at the elbow [21], and carpal tunnel syndrome commonly affects the wrist [8]. At the shoulder, the superior migration of the humeral head potentially causes the impingement of the rotator cuff tendon and the anterior and posterior displacement of the humeral head is associated with joint instability. Considering these pathologies and forces, the ideal system for reporting the intersegmental joint force would be a proximal CS centered on the glenoid fossa. At the elbow, the intersegmental joint force with reference to a distal CS originating on the ulna would make sense to address the posterior-lateral instability of the proximal ulna. Without considering the pathology in the representation, the investigator may be unable to fully explore the clinical question.

Moment representation is more complex than joint force representation because the chosen planes of motion should ideally represent the musculature functions within the body, while recognizing that physiologically, most muscles do not act entirely in one plane of motion. 
JRRD, Volume 46, Number 7, 2009

Table 2.

Wheelchair propulsion coordinate system (CS) representations of joint forces and moments.

\begin{tabular}{|c|c|c|c|c|c|c|}
\hline Joint & Lead Author & Year & $\begin{array}{c}\text { Force } \\
\text { Representation }\end{array}$ & CS Origin & $\begin{array}{c}\text { Moment } \\
\text { Representation }\end{array}$ & CS Origin \\
\hline \multirow[t]{9}{*}{ Shoulder } & Collinger et al. [1] & 2008 & Trunk & $\begin{array}{l}\text { Acromion and trunk } \\
\text { midline ( } 2 \text { marker sets) }\end{array}$ & Humerus & Glenohumeral joint \\
\hline & Desroches et al. [2] & 2008 & NA & NA & Trunk & Trunk midline \\
\hline & Mercer et al. [3] & 2006 & Trunk & Acromion & Trunk & Acromion \\
\hline & Van Drongelen et al. [4] & 2005 & NA & NA & Trunk & Trunk midline \\
\hline & Sabick et al. [5] & 2004 & Trunk & Midline trunk & $\begin{array}{l}\text { Humerus (transverse) and } \\
\text { trunk (sagittal, frontal) }\end{array}$ & $\begin{array}{l}\text { Shoulder joint center/ } \\
\text { trunk center }\end{array}$ \\
\hline & Veeger et al. [6] & 2002 & NA & NA & Trunk & Trunk midline \\
\hline & Koontz et al. [7] & 2002 & Trunk & Shoulder joint center & Trunk & Shoulder joint center \\
\hline & Cooper et al. [8] & 1999 & $\begin{array}{l}3 \text { different trunk } \\
\text { models }\end{array}$ & Shoulder joint center & $\begin{array}{l}3 \text { different trunk } \\
\text { models }\end{array}$ & Shoulder joint center \\
\hline & Kulig et al. [9] & 1998 & Laboratory & Laboratory & Humerus & Shoulder joint center \\
\hline \multirow[t]{2}{*}{ Elbow } & Van Drongelen et al. [4] & 2005 & NA & NA & Forearm & Elbow center \\
\hline & Sabick et al. [5] & 2004 & Humerus & Shoulder joint center & $\begin{array}{l}\text { Forearm (transverse) and } \\
\text { humerus (sagittal, frontal) }\end{array}$ & $\begin{array}{l}\text { Elbow center/shoulder } \\
\text { center }\end{array}$ \\
\hline \multirow[t]{2}{*}{ Wrist } & Sabick et al. [5] & 2004 & Forearm & Elbow center & $\begin{array}{l}\text { Hand (transverse) and forearm } \\
\text { (sagittal, frontal) }\end{array}$ & $\begin{array}{l}\text { Wrist center/elbow } \\
\text { center }\end{array}$ \\
\hline & Boninger et al. [10] & 1997 & Hand & Wrist center & Hand & Wrist center \\
\hline
\end{tabular}

1. Collinger JL, Boninger ML, Koontz AM, Price R, Sisto SA, Tolerico ML, Cooper RA. Shoulder biomechanics during the push phase of wheelchair propulsion: A multisite study of persons with paraplegia. Arch Phys Med Rehabil. 2008;89(4):667-76. [PMID: 18373997] DOI:10.1016/j.apmr.2007.09.052

2. Desroches G, Aissaoui R, Bourbonnais D. Relationship between resultant force at the pushrim and the net shoulder joint moments during manual wheelchair propulsion in elderly persons. Arch Phys Med Rehabil. 2008;89(6):1155-61. [PMID: 18503814] DOI:10.1016/j.apmr.2007.10.040

3. Mercer JL, Boninger M, Koontz A, Ren D, Dyson-Hudson T, Cooper R. Shoulder joint kinetics and pathology in manual wheelchair users. Clin Biomech (Bristol, Avon). 2006;21(8):781-89. [PMID: 16808992] DOI:10.1016/j.clinbiomech.2006.04.010

4. Van Drongelen S, Van der Woude LH, Janssen TW, Angenot EL, Chadwick EK, Veeger DH. Mechanical load on the upper extremity during wheelchair activities. Arch Phys Med Rehabil. 2005;86(6):1214-20. [PMID: 15954062] DOI:10.1016/j.apmr.2004.09.023

5. Sabick MB, Kotajarvi BR, An KN. A new method to quantify demand on the upper extremity during manual wheelchair propulsion. Arch Phys Med Rehabil. 2004;85(7):1151-59. [PMID: 15241767]

6. Veeger HE, Rozendaal LA, Van der Helm FC. Load on the shoulder in low intensity wheelchair propulsion. Clin Biomech (Bristol, Avon). 2002;17(3):211-18. [PMID: 11937259] DOI:10.1016/S0268-0033(02)00008-6

7. Koontz AM, Cooper RA, Boninger ML, Souza AL, Fay BT. Shoulder kinematics and kinetics during two speeds of wheelchair propulsion. J Rehabil Res Dev. 2002;39(6):635-49. [PMID: 17943666]

8. Cooper RA, Boninger ML, Shimada SD, Lawrence BM. Glenohumeral joint kinematics and kinetics for three coordinate system representations during wheelchair propulsion. Am J Phys Med Rehabil. 1999;78(5):435-46. [PMID: 10493454] DOI:10.1097/00002060-199909000-00006

9. Kulig K, Rao SS, Mulroy SJ, Newsam CJ, Gronley JK, Bontrager EL, Perry J. Shoulder joint kinetics during the push phase of wheelchair propulsion. Clin Orthop Relat Res. 1998;354:132-43. [PMID: 9755772] DOI:10.1097/00003086-199809000-00016

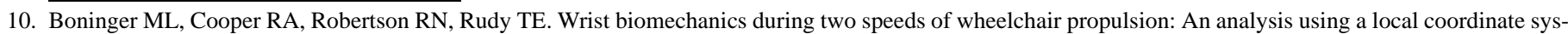
tem. Arch Phys Med Rehabil. 1997;78(4):364-72. [PMID: 9111455] DOI:10.1016/S0003-9993(97)90227-6

$\mathrm{NA}=$ data not present in referenced article.

Schache and Baker investigated lower-limb joint moments and their clinical interpretation when differing reporting methods are used [22]. In choosing the most appropriate reference frame, Schache and Baker explained that the choice should be based on which CS is "most useful in understanding the biomechanics of gait with or without pathology" [22]. This statement is of global importance in biomechanics and can be applied equally to the UL. Their final recommendation was that a nonorthogonal JCS provides an implicit link to muscle activity and offers a clinically useful representation of what a joint moment actually represents [22]. For the same reasons, we can argue that the 
nonorthogonal JCS is appropriate for UL joints as well. To elucidate this point, we consider the elbow joint. With the elbow flexed to $90^{\circ}$, the abduction-adduction moment based on the proximal CS would be the same as the supinationpronation moment based on the distal CS. This problem only grows when we consider the shoulder. Changes in what is considered an abduction-adduction moment versus a flexion-extension moment alter dramatically as soon as the humerus segment undergoes any axial rotation. Wu et al. experienced the same problem when trying to clearly represent shoulder kinematics with a classic Cardan sequence; hence, the ISB recommends using the JCS with an Eulerian sequence [18]. The JCS provides the functional and anatomical relevance for moment representations that is incompatible with orthogonal axes [23].

\section{CONCLUSIONS}

We address the inconsistency of kinetic reporting in the wheelchair literature that attempts to address the clinical problems experienced by manual wheelchair users. This discussion is not relevant in purely academic practices but is put forth for clinically directed motivations. In the future, researchers should appropriately select a CS that can address the clinically driven questions for which they seek answers. Whether attached proximal or distal to a joint, CSs for force and moment representation should be centered within the joint of interest. The JCS offers a less ambiguous and more anatomically relevant representation of joint moments and a clear demonstration of muscle activity. Future implementation of clinically significant standard practices will advance the field toward a full understanding of the link between wheelchair propulsion and pathology.

\section{ACKNOWLEDGMENTS}

\section{Author Contributions:}

Study concept and design: M. M. B. Morrow, W. J. Hurd, K. R. Kaufman, K. An.

Drafting of manuscript: M. M. B. Morrow.

Critical revision of manuscript for important intellectual content:

M. M. B. Morrow, W. J. Hurd, K. R. Kaufman, K. An.

Obtained funding: K. An, K. R. Kaufman.

Study supervision: K. An, K. R. Kaufman.

Financial Disclosures: The authors have declared that no competing interests exist.
Funding/Support: This material was based on work supported by the National Institutes of Health (grant R01HD4878).

Additional Contributions: We acknowledge Kathie Bernhardt and Diana Hansen for their assistance with subject testing and data processing. Melissa M. B. Morrow has earned her doctorate since the time of manuscript acceptance.

\section{REFERENCES}

1. Gellman H, Sie I, Waters RL. Late complications of the weight-bearing upper extremity in the paraplegic patient. Clin Orthop Relat Res. 1988;233:132-35. [PMID: 3402118]

2. Wylie EJ, Chakera TM. Degenerative joint abnormalities in patients with paraplegia of duration greater than 20 years. Paraplegia. 1988;26(2):101-6. [PMID: 3412779]

3. Pentland WE, Twomey LT. Upper limb function in persons with long term paraplegia and implications for independence: Part II. Paraplegia. 1994;32(4):219-24. [PMID: 8022631]

4. Bayley JC, Cochran TP, Sledge CB. The weight-bearing shoulder. The impingement syndrome in paraplegics. J Bone Joint Surg Am. 1987;69(5):676-78. [PMID: 3597466]

5. Curtis KA, Drysdale GA, Lanza RD, Kolber M, Vitolo RS, West R. Shoulder pain in wheelchair users with tetraplegia and paraplegia. Arch Phys Med Rehabil. 1999;80(4):453-57. [PMID: 10206610] DOI:10.1016/S0003-9993(99)90285-X

6. Sie IH, Waters RL, Adkins RH, Gellman H. Upper extremity pain in the postrehabilitation spinal cord injured patient. Arch Phys Med Rehabil. 1992;73(1):44-48. [PMID: 1729973]

7. Mercer JL, Boninger M, Koontz A, Ren D, Dyson-Hudson T, Cooper R. Shoulder joint kinetics and pathology in manual wheelchair users. Clin Biomech (Bristol, Avon). 2006;21(8): 781-89. [PMID: 16808992]

DOI:10.1016/j.clinbiomech.2006.04.010

8. Boninger ML, Cooper RA, Robertson RN, Rudy TE. Wrist biomechanics during two speeds of wheelchair propulsion: An analysis using a local coordinate system. Arch Phys Med Rehabil. 1997;78(4):364-72. [PMID: 9111455] DOI:10.1016/S0003-9993(97)90227-6

9. Boninger ML, Cooper RA, Baldwin MA, Shimada SD, Koontz A. Wheelchair pushrim kinetics: Body weight and median nerve function. Arch Phys Med Rehabil. 1999; 80(8):910-15. [PMID: 10453767] DOI:10.1016/S0003-9993(99)90082-5

10. Kulig K, Rao SS, Mulroy SJ, Newsam CJ, Gronley JK, Bontrager EL, Perry J. Shoulder joint kinetics during the push phase of wheelchair propulsion. Clin Orthop Relat Res. 1998;354:132-43. [PMID: 9755772] DOI:10.1097/00003086-199809000-00016

11. Robertson RN, Boninger ML, Cooper RA, Shimada SD. Pushrim forces and joint kinetics during wheelchair propulsion. Arch Phys Med Rehabil. 1996;77(9):856-64. 
[PMID: 8822674]

DOI:10.1016/S0003-9993(96)90270-1

12. Collinger JL, Boninger ML, Koontz AM, Price R, Sisto SA, Tolerico ML, Cooper RA. Shoulder biomechanics during the push phase of wheelchair propulsion: A multisite study of persons with paraplegia. Arch Phys Med Rehabil. 2008;89(4):667-76. [PMID: 18373997]

DOI:10.1016/j.apmr.2007.09.052

13. Koontz AM, Yang Y, Price R, Tolerico ML, DiGiovine CP, Sisto SA, Cooper RA, Boninger ML. Multisite comparison of wheelchair propulsion kinetics in persons with paraplegia. J Rehabil Res Dev. 2007;44(3):449-58.

[PMID: 18247241]

DOI:10.1682/JRRD.2006.05.0048

14. Koontz AM, Cooper RA, Boninger ML, Souza AL, Fay BT. Shoulder kinematics and kinetics during two speeds of wheelchair propulsion. J Rehabil Res Dev. 2002;39(6): 635-49. [PMID: 17943666]

15. Sabick MB, Kotajarvi BR, An KN. A new method to quantify demand on the upper extremity during manual wheelchair propulsion. Arch Phys Med Rehabil. 2004;85(7): 1151-59. [PMID: 15241767]

16. Van Drongelen S, Van der Woude LH, Janssen TW, Angenot EL, Chadwick EK, Veeger DH. Mechanical load on the upper extremity during wheelchair activities. Arch Phys Med Rehabil. 2005;86(6):1214-20. [PMID: 15954062] DOI:10.1016/j.apmr.2004.09.023

17. Veeger HE, Rozendaal LA, Van der Helm FC. Load on the shoulder in low intensity wheelchair propulsion. Clin Biomech (Bristol, Avon). 2002;17(3):211-18. [PMID: 11937259] DOI:10.1016/S0268-0033(02)00008-6

18. Wu G, Van der Helm FC, Veeger HE, Makhsous M, Van Roy P, Anglin C, Nagels J, Karduna AR, McQuade K, Wang X, Werner FW, Buchholz B; International Society of
Biomechanics. ISB recommendation on definitions of joint coordinate systems of various joints for the reporting of human joint motion-Part II: Shoulder, elbow, wrist and hand. J Biomech. 2005;38(5):981-92. [PMID: 15844264] DOI:10.1016/j.jbiomech.2004.05.042

19. Cooper RA, Boninger ML, Shimada SD, Lawrence BM. Glenohumeral joint kinematics and kinetics for three coordinate system representations during wheelchair propulsion. Am J Phys Med Rehabil. 1999;78(5):435-46.

[PMID: 10493454] DOI:10.1097/00002060-199909000-00006

20. Desroches G, Aissaoui R, Bourbonnais D. Relationship between resultant force at the pushrim and the net shoulder joint moments during manual wheelchair propulsion in elderly persons. Arch Phys Med Rehabil. 2008;89(6):1155-61.

[PMID: 18503814$]$ DOI:10.1016/j.apmr.2007.10.040

21. Lin VW, Cardenas DD, Cutter NC, Frost FS, Hammond MC, Lindblom LB, Perhash I, Waters R, Woolsey RM, editors. Spinal cord medicine: Principles and practice. New York (NY): Demos; 2003.

22. Schache AG, Baker R. On the expression of joint moments during gait. Gait Posture. 2007;25(3):440-52.

[PMID: 17011192] DOI:10.1016/j.gaitpost.2006.05.018

23. Dumas R, Chèze L. 3D inverse dynamics in non-orthonormal segment coordinate system. Med Biol Eng Comput. 2007; 45(3):315-22. [PMID: 17252233] DOI:10.1007/s11517-006-0156-8

Submitted for publication December 23, 2008. Accepted in revised form May 27, 2009. 